\title{
Capital público e investimentos privados no Nordeste brasileiro: Bahia, Pernambuco, Rio Grande do Norte e Ceará
}

\section{Public capital and private investments in Brazilian Northeast: Bahia, Pernambuco, Rio Grande do Norte and Ceará}

\author{
Marília Natacha de Freitas Silva (FREITAS SILVA, M. N. de)*
}

\begin{abstract}
RESUMO - O litoral nordestino brasileiro vem atraindo empreendimentos turísticos que incorporam o componente imobiliário a suas estruturas, intitulado pela mídia, de turismo-imobiliário. Estes empreendimentos foram possíveis graças à liberação financeira de mercado e as políticas de turismo no Nordeste, promovendo mudanças significativas na reordenação dos seus espaços litorâneos. Nesse caso, o Estado tem um papel fundamental na consolidação destas práticas, investindo, sobretudo em infraestrutura logística (aeroportos e rodovias) em sentido paralelo ao litoral com a esperança de atrair volumes de investimentos tanto de âmbito nacional como internacional. Portanto no presente artigo se tem como objetivo identificar e espacializar as políticas públicas de turismo em suas diferentes etapas e consequentemente os investimentos privados relacionados a atividade turística para um entendimento da lógica de produção do espaço litorâneo dos estados: Bahia, Pernambuco, Rio Grande do Norte e Ceará. O trabalho foi construído em três etapas: levantamento bibliográfico sobre o tema; análise de dados secundários, junto aos órgãos responsáveis e ao final; a elaboração de cartogramas. Foi possível identificar a relação e a união entre as políticas de turismo e o capital privado empregado ao longo do litoral nordestino.
\end{abstract}

Palavras-Chaves: Turismo; Políticas Públicas de Turismo; Capital Privado; Produção do Espaço.

ABSTRACT - The Brazilian Northeastern Coast has been attracting tourist enterprises that incorporate the real estate component to their structures, titled by the media as real estate tourism. This area development was possible because the market financial liberation and the tourism policies in the Northeast, promoting significant changes in the reordering of Northeastern coastal areas. In this case, the State has a fundamental role in consolidation of these practices, investing mainly in logistics infrastructure (airports and highways) along the coastline in the hope of attracting both national and international investment volumes. Therefore, in this article, the objective was to identify and spatialize the public policies of tourism in its different stages and consequently the private investments related to tourist activity for an understanding of the logic of production of the coastal space in: Bahia, Pernambuco, Rio Grande do Norte and Ceará. This paper was executed in three phases: bibliographical survey on the theme; analysis of secondary data, with the responsible public agents and at the end; the development of

\footnotetext{
* Doutoranda em Turismo e Geografia em regime de cotutela entre a Universidade de Alicante/Espanha e a Universidade Federal do Ceará (UFC). Graduação e Mestrado em Geografia pela Universidade Federal do Ceará (UFC). Integrante do Observatório das Metrópoles/Núcleo Fortaleza. Professora do Departamento de Sociologia I, da Universidade de Alicante/Espanha. Endereço físico para correspondência: Universidad de Alicante. Carretera de San Vicente del Raspeig s/n, 03690, San Vicente del Raspeig/Alicante (España). E-mail: mnsilva.ufc@gmail.com
} 
cartograms. It was possible to identify the relationship and the union between tourism policies and private capital invested along the Brazilian Northeastern Coast.

Key words: Tourism; Public Tourism policies; Private Capital; Space production. 


\section{INTRODUÇÃO}

$\mathrm{Na}$ segunda metade do século XX, o mundo foi marcado por importantes mudanças sociopolíticas. Dentre as diversas alterações nos modos de produção e nas relações de trabalho, destaca-se o setor terciário, tendo o turismo recebido o maior destaque (ASSIS, 2002). O turismo, como umas das novas formas de reprodução do capital, é inserido na dinâmica da acumulação capitalista para responder as crises globais e ampliadas do capital mundial.

A pesar das antigas origens do turismo como prática social, o desenvolvimento do turismo como atividade econômica tem sido produzido em umas poucas décadas recentes. O turismo se converteu com rapidez em uma atividade fonte de negócios, e em um setor da economia internacional e em uma "megaindústria" global (JAFARI, 2005). E, por isso, para muitos autores e gestores públicos e privados, o fenômeno do turismo passa a ser fundamental no processo de desenvolvimento local, a partir da década de 50 - principalmente nos países da América Latina - que passam a recorrer a financiamentos para impulsionar o turismo em prol do desenvolvimento (TOSUN; JEKINS, 1998).

A evolução do pensamento sobre o turismo e a sua contribuição para o desenvolvimento, marca uma mudança sociopolítica, econômica e espacial no terceiro mundo. Como consequência, conforme Archer e Cooper (2001), Streeten (2006) e Sinclair e Stabler (2009) modelos de desenvolvimento através do turismo foram incorporados em regiões tropicais baseados na sinonímia entre o desenvolvimento e crescimento econômico e na utilização de modelos e experiências "de sucesso" dos países desenvolvidos.

Essa associação entre o turismo e as teorias de desenvolvimento é feita tomando como pressuposto que a atividade tem potencial para corrigir as desigualdades sociais, através da geração de emprego e renda e do seu efeito multiplicador da receita gerada. Neste contexto, países da Ásia, África e América Latina tomam o turismo como o possível "milagre" e "motor" de desenvolvimento para suas economias (BRITTON, 1982; KRIPPENDORF, 1982; KO, 2001).

No Brasil, especificamente na região Nordeste, - uma região estruturalmente subdesenvolvida - as expectativas de um crescimento induzido através do turismo eram 
particularmente fortes, e, por isso os poderes públicos não duvidaram em liberar incentivos excepcionais para a inserção desta região no cenário turístico internacional (GOMES, 1991; BENI, 2001; 2002; DIAS, 2003; entre outros).

Tais incentivos geraram um progresso que só foi possível, graças ao conjunto de políticas que fomentou a construção de infraestrutura básica para a constituição das práticas litorâneas e, também, para a construção de uma imagem positiva do semiárido, que por muito tempo foi visto como região problema, que contribuiu para a reestruturação socioespacial de comunidades e cidades na região (DANTAS, 2000).

Nessa perspectiva, no presente artigo se teve por objetivo identificar e espacializar as políticas públicas de turismo em suas diferentes etapas e consequentemente os investimentos privados relacionados à atividade turística para um entendimento da lógica de produção do espaço litorâneo dos estados: Bahia, Pernambuco, Rio Grande do Norte e Ceará. Para alcançar os objetivos, o trabalho foi procedido em três etapas principais: Na primeira fez-se um levantamento bibliográfico, acerca dos temas: turismo, Estado e planejamento, através de livros, trabalhos acadêmicos e periódicos online. A segunda etapa consistiu em levantamento documental na base de dados do Ministério do Turismo (MTur); Banco do Nordeste Brasileiro (BNB); Comissão de Financiamentos Externo (CONFIEX); Portal da Transparência dos Recursos Federais, além de dissertações e teses. E, a terceira na espacialização e análise das principais ações fomentadas pelas políticas públicas de turismo e dos investimentos de capital privado na região Nordeste.

\section{DESENVOLVIMENTO, TURISMO E PLANEJAMENTO TURÍSTICO: UMA COMPLEXA RELAÇÃO}

Na mesma intensidade com que tem sido comum referir-se ao turismo a partir de seu propalado poder de desenvolvimento, recorre-se ao planejamento como instrumento imprescindível para o bom funcionamento da atividade turística. Ao se abordar o turismo e sua relação com o desenvolvimento, quase de imediato se suscita por grande parte dos estudiosos da área a discussão sobre a necessidade direta de planejamento (LOHMANN; PANOSSO NETTO, 2008). 
Apesar dos benefícios gerados para uma comunidade, o turismo pode, em virtude de seu expressivo crescimento, provocar efeitos mais nocivos do que benéficos e, portanto, Goeldner et al. (2002), ressaltam que o turismo mal planejado e mal desenvolvido pode trazer sérios problemas. Sobre o papel do planejamento para a atividade turística, segundo Solha e Tulik (2004, p. 9), no turismo, "as preocupações em se estabelecer políticas para o setor só aparecem quando este adquire importância econômica, ou quando começa a causar transtorno". Anteriormente a estas duas situações, as autoras reiteram que a atividade se caracteriza pela espontaneidade, com pouco ou nenhum controle de seu desenvolvimento, prevalecendo apenas as leis de mercado.

No intuito de constatar a relação estabelecida entre as principais perspectivas de planejamento turístico e as abordagens de desenvolvimento identificadas por meio da literatura de turismo, sugere-se a leitura do quadro síntese (QUADRO 1). Nesse quadro estão relacionadas as abordagens de desenvolvimento selecionadas, bem como suas perspectivas características fundamentais e os preceitos das principais formas de compreensão do planejamento no âmbito do turismo, resumido por Malta e Barbosa (2013).

QUADRO 1 - COMPARATIVO ENTRE ABORDAGENS DO DESENVOLVIMENTO, PLANEJAMENTO E TURISMO.

\begin{tabular}{|ll|lll|}
\hline Abordagem & \multicolumn{1}{c}{$\begin{array}{c}\text { Características } \\
\text { principais }\end{array}$} & \multicolumn{1}{c}{$\begin{array}{c}\text { Estratégias } \\
\text { propostas }\end{array}$} & $\begin{array}{c}\text { Perspectivas de } \\
\text { planejamento } \\
\text { turístico }\end{array}$ & $\begin{array}{c}\text { Características } \\
\text { principais }\end{array}$ \\
\hline $\begin{array}{l}\text { Econômica/ } \\
\text { Utilitarista }\end{array}$ & $\begin{array}{l}\text { Enfoque excessivo da } \\
\text { dimensão melhoria, } \\
\text { sobretudo econômica. }\end{array}$ & $\begin{array}{l}\text { Estimulo à } \\
\text { promoção do } \\
\text { turismo, focando } \\
\text { a concorrência e } \\
\text { competição. } \\
\text { Enfase a } \\
\text { capacidade de } \\
\text { gerar emprego e } \\
\text { renda. }\end{array}$ & $\begin{array}{l}\text { Fomento ou } \\
\text { impulsionista. }\end{array}$ & $\begin{array}{l}\text { A atitude } \\
\text { simplista de que o } \\
\text { desenvolvimento } \\
\text { é sempre bom. A } \\
\text { população não } \\
\text { está envolvida no } \\
\text { planejamento. }\end{array}$ \\
& & & Econômico/ \\
& & & $\begin{array}{l}\text { Turismo como } \\
\text { meio de promover } \\
\text { crescimento em } \\
\text { áreas rurais ou } \\
\text { subdesenvolvidas, } \\
\text { promovendo } \\
\text { emprego e renda. }\end{array}$ \\
\hline
\end{tabular}

Continua... 
... Continuação.

\begin{tabular}{|c|c|c|c|c|}
\hline \multirow[t]{2}{*}{ Sustentável } & \multirow{2}{*}{$\begin{array}{l}\text { Incorporação de } \\
\text { outras facetas do } \\
\text { desenvolvimento, } \\
\text { além da econômica, a } \\
\text { ambiental, cultural e } \\
\text { social. }\end{array}$} & \multirow{2}{*}{$\begin{array}{l}\text { Promover } \\
\text { atividades que } \\
\text { contemplam o } \\
\text { desenvolvimento } \\
\text { que ultrapassa a } \\
\text { dimensão apenas } \\
\text { econômica }\end{array}$} & Física/espacial & $\begin{array}{l}\text { O turismo tratado } \\
\text { como indústria } \\
\text { limpa e ecológica }\end{array}$ \\
\hline & & & Sustentável & $\begin{array}{l}\text { Uma forma } \\
\text { integrada de } \\
\text { planejamento que } \\
\text { procura garantir, } \\
\text { ao longo prazo, } \\
\text { um mínimo de } \\
\text { deterioração de } \\
\text { recursos. }\end{array}$ \\
\hline $\begin{array}{l}\text { Comunitária/ } \\
\text { local }\end{array}$ & $\begin{array}{l}\text { Enfoque direcionado } \\
\text { a escala do local, } \\
\text { privilegia a } \\
\text { participação da } \\
\text { população ao longo } \\
\text { do processo de } \\
\text { desenvolvimento. }\end{array}$ & $\begin{array}{l}\text { Contemplar ações } \\
\text { e projetos que se } \\
\text { baseiam no poder } \\
\text { de mobilização e } \\
\text { engajamento dos } \\
\text { agentes sociais e a } \\
\text { capacidade dos } \\
\text { mesmos em } \\
\text { pensar o local de } \\
\text { forma integral. }\end{array}$ & Comunitário & $\begin{array}{l}\text { Enfase no } \\
\text { contexto social e } \\
\text { político, no qual, } \\
\text { o turismo ocorre. } \\
\text { Defende um } \\
\text { maior controle } \\
\text { local sobre o } \\
\text { processo de } \\
\text { desenvolvimento }\end{array}$ \\
\hline
\end{tabular}

FONTE: Malta e Barbosa (2013).

Vale destacar a proximidade estabelecida entre os conteúdos de ambos os elementos, no sentido de evidenciar a estreita relação entre o planejamento e os desdobramentos advindos dos processos de desenvolvimento. Ainda que, de início, seja difícil estabelecer uma correlação entre as noções dispostas no quadro, em virtude da não correspondência numérica entre eles, é possível perceber que as abordagens de desenvolvimento exercem uma clara influência entre as perspectivas de planejamento turístico e vice-versa.

Nesse sentido, é de suma importância introduzir, mesmo sumariamente, as principais fases da política, pelas quais, mundialmente, a atividade turística passou, abrangendo, para tanto, o período a partir de 1950. O primeiro momento, que compreende o período de 1950 a 1970 (abordagem utilitarista/econômica), caracterizouse pela expansão do turismo de massa, quando eram comuns as políticas de fomento, cujo objetivo principal era o aumento do fluxo de visitantes.

Em seguida, entre os anos de 1970 a 1985 (abordagem sustentável), observou-se o início de um período no qual as políticas começavam a identificar o turismo como agente de desenvolvimento. Em virtude desse reconhecimento, verificou-se um aumento do envolvimento governamental e o consequente investimento em infraestrutura nas localidades definidas como turísticas. Do ano de 1985 em diante (abordagem 
comunitária/local), entra-se na terceira fase, um novo momento, estimulado por questões acadêmicas e científicas.

A abordagem utilitarista/econômica, identificada como umas das principais e mais recentes formas de se referir ao desenvolvimento dentre aquelas implícitas nos estudos do turismo, surge com maior frequência em análises que buscam ressaltá-lo em virtude de seu efeito multiplicador enquanto atividade econômica. Nota-se a relação direta entre a noção de desenvolvimento econômico e a perspectiva de planejamento, que se volta para o incremento econômico do turismo (MALTA; BARBOSA, 2013).

Em termos conceituais, houve em meados do século XX, uma revolta generalizada contra a "camisa de força" das definições econômicas do desenvolvimento, que restringiam suas metas a indicadores quantitativos e relativamente irrelevantes (ESTEVA, 2000). A partir, daquele momento, questionava-se até que ponto era possível explicar o desenvolvimento empregado apenas em termos econômicos. Como reflexo deste processo, desde o início da década de 1990 o termo sustentável passa a ser amplamente utilizado no debate sobre o desenvolvimento, atingindo diversos setores e atividades econômicas, dentre elas, o turismo.

Por terem se intensificado as pesquisas que analisam os impactos socioespaciais do turismo, verificando que a atividade turística acaba, muitas vezes, alavancando um processo de desenvolvimento altamente impactante, ambiental e socialmente, cresce, também de maneira significativa nos últimos anos, o debate sobre as formas de turismo que buscam contrapor ao turismo convencional ou de massa. Portanto, já a segunda corrente exposta, enxerga o crescimento e desenvolvimento como ideais distintos.

Essa corrente considera o crescimento uma condição indispensável para o processo de desenvolvimento, mas não uma condição suficiente. $\mathrm{O}$ crescimento é visto então como uma variação quantitativa, enquanto que o desenvolvimento requer mudanças qualitativas no modo de vida das pessoas. Essa noção requer mudanças nas estruturas econômicas, sociais, políticas e institucionais, com simultânea melhoria da produtividade e da renda média dos agentes envolvidos no processo produtivo.

As abordagens sustentáveis de desenvolvimento, por sua vez, conforme, enfatizam vários autores, surgem a partir de meados da década de 1980, sendo associadas "a uma mudança de enfoque na definição da problemática ambiental, de 
visões eminentemente preservacionistas dos anos de 1960 e 1970, à associação entre crescimento econômico e preocupação ambiental" (COSTA, 2008, p. 80).

Em especial, no que se refere aos estudos voltados para o turismo, a dimensão sustentável do desenvolvimento é comumente associada à atividade enquanto um adjetivo que qualifica e agrega valor, sobretudo comercial, à mesma. Ou seja, o turismo sustentável corresponde a um termo específico que denota a aplicação do desenvolvimento sustentável ao contexto particular do turismo. Como acrescenta Candiotto e Zanetti (2009, p. 2) "com a emergência da ideia de desenvolvimento sustentável, o termo turismo sustentável vem cada vez mais ganhando espaço no debate acadêmico, bem como no marketing turístico".

Percebe-se que, assim como no conceito de desenvolvimento sustentável, o turismo sustentável baseia-se na dimensão econômica e incorpora timidamente as dimensões ambiental, social e cultural, entendendo-as, "como oportunidades e recursos para a continuidade da atividade turística" conforme visão de Candiotto (2007, p. 2). Nesse contexto, a categoria de sustentável é muito mais um rótulo que de fato uma orientação para a promoção da atividade turística. Portanto o turismo adquire o status de “sustentável" para que possa ser vendido, uma vez que traz vantagens econômicas (BUTLER, 1998),

A terceira das abordagens identificadas - comunitária/local/humana - é apropriada pelos estudos de turismo como uma "nova" orientação, que visa transformar o caráter estritamente predatório e econômico apresentado pela atividade (RODRIGUES, 1997; BENEVIDES, 1997). Em síntese, a proposta baseia-se no conceito de desenvolvimento local como princípio orientador para a construção de um modelo de promoção do turismo, distinto do prevalecente. A abordagem de desenvolvimento identificada como comunitária/local, além de agregar valor ao tipo de turismo que inspira, é apresentada pelos trabalhos que a abordam como um "guia de orientação" para a construção de "outro" modelo de promoção da atividade turística, direcionada para a escala local e focada nos sujeitos sociais que participam deste processo.

Vale esclarecer que se convencionou trabalhar as dimensões comunitária e local conjuntamente, dentro de uma única abordagem, já que, ainda que os trabalhos possam se referir a essas dimensões de forma separada, elas partem, normalmente, de um 
mesmo conceito de desenvolvimento, e, portanto, possuem objetivos e diretrizes similares. Em um mesmo sentido, Reis (2005, p. 7) considera que, em termos de territorialidade, "a designação desenvolvimento local, embora não exclua, pode abranger ou até se confundir com desenvolvimento urbano, rural e comunitário".

Portanto, propor o desenvolvimento com base local "significa contrariar a racionalidade econômica vigente e fortalecer o que Milton Santos ${ }^{1}$ designa por 'contra finalidades' que são localmente geradas [...]" (SANTOS, 1996 apud RODRIGUES, 1997, p. 58 $)^{2}$. Ou seja, torna-se necessário, para tanto, revisitar e questionar diversos conceitos prevalecentes no modelo tradicional, como, por exemplo, o conceito de eficiência, que se associa à noção de maximização da produtividade.

\section{ESTADO E $\mathrm{O}$ PLANEJAMENTO DO TURISMO PARA DESENVOLVIMENTO LOCAL}

Muitas são as discussões que tentam projetar as bases conceituais que levam um maior entendimento do turismo, em função das promoções assumidas por este enquanto fenômeno econômico e social em vários países do mundo, além dos impactos que dele suscitam e o envolvem. Nesse sentido, conforme, Endres (2008) o processo de planejamento do turismo tem relação direta com o desenvolvimento, que se faz de fato através da melhoria da qualidade de vida dos habitantes de um país, de uma região ou de uma localidade.

O que seria planejamento? De acordo com Cruz (2006) planejamento é algo que remete sempre ao futuro, já que não se pode planejar o passado ou o presente. Por isso, planejar significa, sempre, projetar o futuro que se deseja. Mas para projetar o futuro é preciso olhar para o passado e identificar os erros, assim como, é necessário olhar para o presente, e diagnosticar a realidade atual e, a partir disso, pensar sobre os cenários futuros que se almeja construir.

Em segundo lugar, a mesma autora, afirma que o planejamento é sempre uma ação racional e, como tal, é embutido de ideologia. Planejamento é meio e não fim. O

\footnotetext{
${ }^{1}$ SANTOS, M. A natureza do espaço. Técnica e tempo, razão e emoção. São Paulo: Hucitec, 1996.

${ }^{2}$ SANTOS, M. A natureza do espaço. Técnica e tempo, razão e emoção. São Paulo: Hucitec, 1996.
} 
planejamento é um processo político ideológico, que exprime anseios, objetivos, visões de mundo dos atores sociais que o conduzem. E em terceiro lugar, o planejamento é um processo, e, por isso, comporta uma gama de ações. A organização de um dado setor da vida social e somente pode ser resultado de um processo contínuo de planejamento.

Pelo prisma da análise política sobre a relação turismo, planejamento e desenvolvimento, entender o papel do Estado torna-se indispensável. Pois, a ele cabe a tarefa de propiciar estratégias locais e sustentáveis de desenvolvimento que procurem realizar os objetivos de aumento da produtividade e da competitividade do sistema produtivo, de melhoria da distribuição de renda e da conservação dos recursos naturais e do patrimônio histórico e cultural (ENDRES, 2008; CRUZ, 2006).

Tais estratégias devem ser instrumentadas através de ações que permitam a ele uma maior flexibilidade e complexidade institucional, que se evidenciam por um ambiente institucional ao qual o setor produtivo está atrelado, caracterizado por densas redes de relações envolvendo empresas, instituições de ensino, pesquisa, associações de empresários, sindicatos e governos locais que fornecem ao setor econômico específico. O Estado deve atuar como um instrumento integrador para melhorar o comportamento de cada um dos segmentos que compõem sua cadeia produtiva para que a eficiência dos mesmos possibilite o desenvolvimento em suas bases locais (ENDRES, 2008).

Por essa perspectiva, aprofundar o entendimento de como a atividade turística pode contribuir para o desenvolvimento local demanda identificar e analisar as ações do Estado, assim como interpretar a repercussão de suas políticas sobre a sociedade. Dentre algumas referências sobre turismo, políticas e desenvolvimento que são indicativos importantes que fundamentam tais percepções, o estudo de Molina e Rodriguez (2001), aborda sobre o fracasso do planejamento governamental nos países da América Latina em fazer do turismo uma atividade dinamizadora de desenvolvimento social. Os autores analisam as realidades latino-americanas, em geral, a brasileira, e afirmam, que as ações governamentais no setor turístico orientadas para o desenvolvimento social pouco se efetivaram.

$\mathrm{Na}$ constatação dos autores, as ações de planejamento turístico voltadas apenas para o crescimento econômico só reforçaram as relações de dependência com os países desenvolvidos e quase nada para "promover a modificação de um estado de coisas para níveis de uma ordem maior, com base nos interesses próprios da região" (MOLINA; 
RODRIGUEZ, 2001, p. 40). Grosso modo, quando o estado orienta suas políticas conforme as regras do consumo e do mercado internacional, em um contexto de planejamento forjado no imediatismo o turismo ao invés de melhorar a qualidade de vida sobre a sociedade, ao contrário, pode contribuir com impactos sociais irreversíveis.

O desenvolvimento do turismo deve ser um projeto construído coletivamente e não uma resposta a interesses particulares, de grupos sociais específicos. O planejamento do turismo, seja ele numa escala regional ou local, não se dá sobre um espaço "plano" e "vazio", um receptáculo puro e simples de ações das pessoas como chama atenção Cruz (2006), ao contrário, este planejamento se dá sobre um espaço concreto, herdado, histórico e socialmente construído.

Um elemento fundamental de uma política de turismo, eficaz e socialmente aceita, é o conceito de responsabilidade compartilhada. Esta consiste em trocar uma visão em que de um lado existem os agentes infratores e do outro lado o Estado fiscalizador - punidor, por outra na qual há uma responsabilização de todos os agentes sociais (DE ALMEIDA, 2004).

Ainda segundo a mesma autora, o diálogo e o bom senso, bem como transparência da tomada de decisão são condições necessárias para uma efetiva corresponsabilidade. Para isso, deve-se levar em conta que tanto a participação efetiva da população local no planejamento e na gestão do turismo, bem como as peculiaridades naturais e culturais que singularizam os lugares constituem referências a serem incorporadas em programas de estímulo ao empreendedorismo e de capacitação profissional, destinados a segmentos da população.

Um novo conteúdo político desse planejamento para o desenvolvimento local deve, portanto, significar outras formas de solidariedade e de organização espacial. De Almeida (2004), faz referência à importância de uma cooperação intermunicipal que está na base das formas associativas, juntamente com a participação da comunidade e a parceria entre o público e privado. O estado é presença importante principalmente naquelas frentes "pioneiras" nas quais a atividade turística desponta como promotora do desenvolvimento local.

Partindo das premissas acima arroladas, fazer do turismo um instrumento para o desenvolvimento local e regional requer: 1) um posicionamento proativo por parte das sociedades locais; 2) o necessário discernimento de que o turismo é apenas uma 
pequena parte do complexo de relações que é a vida em sociedade, ou seja, por mais importante que o turismo possa ser, a vida envolve outras muitas questões como política, saúde, educação etc.; e 3) um olhar atento sobre o território, sua história, sua gente, suas demandas e a busca permanente pelo encontro de um equilíbrio entre os diferentes interesses envolvidos no desenvolvimento do turismo: interesses dos turistas, dos comerciantes, dos governos, da população em geral (CRUZ, 2006).

Se, de um lado, o turismo pode teoricamente contribuir para "aliviar a pobreza" de outro, tem sido na prática, segundo Cruz (2006) responsável por sua redistribuição espacial. Ao tornar determinadas porções do território atrativas para trabalhadores com baixa qualificação profissional, dado que grande parte dos postos de trabalho diretamente associados ao turismo estão na informalidade ou dizem respeito a empregos mal remunerados, o turismo tem atraído contingentes de pessoas pobres para lugares receptores de fluxos, na busca por sua inserção no mundo do trabalho.

Portanto, conforme Cruz (2006) se existe teoricamente alguma possibilidade de o turismo contribuir para "aliviar a pobreza", então o planejamento do turismo como instrumento para o alcance de tal fim deveria: 1) apropriar-se do conhecimento já produzido no país acerca da distribuição espacial da pobreza; 2) diagnosticar as causas da pobreza para além das explicações óbvias, com aquelas que se restringem a questões estruturais; 3) identificar eventuais fatores regionais perpetuadores da pobreza ou dificuldades de sua superação, de modo a construir um referencial que ao fim e ao cabo permita avaliar as possibilidades de o turismo contribuir para a sua superação.

Dadas as colocações acima, considera-se ter ficado clara a necessidade de as políticas publicas de turismo integrarem-se a outras políticas setoriais, posto que a atividade do turismo não está apartada de um contexto social, econômico e político, e por si, sozinha, nunca contribuirá para o desenvolvimento das comunidades (CRUZ, 2006). Portanto um turismo desejável somente ocorrerá, repetindo o que já foi comentado antes, com a gestão integrada dos planos municipais, manutenção da qualidade ambiental, a participação ativa da sociedade local e o associativismo coparticipativo dos municípios envolvidos. Aí, sim, se poderia começar um novo discurso para, além do desenvolvimento do turismo, que contribuiu, de fato, ao desenvolvimento local (DE ALMEIDA, 2004). 


\section{RESULTADOS E DISCUSSÕES}

O turismo e o capital imobiliário consistem em uma realidade nos estados do Nordeste, principalmente no caso dos estados da Bahia, Pernambuco, Rio Grande do Norte e Ceará. O setor imobiliário, assim como as atividades turísticas, assumiram tal magnitude graças ao esforço continuado dos estados na implementação de políticas públicas de promoção do turismo. Dada a importância do PRODETUR/NE como um “divisor de águas”, apresentaremos as principais ações do Prodetur em todas suas etapas para um entendimento sobre a atual produção e reconfiguração dos espaços litorâneos para atender as recentes práticas marítimas modernas (PEREIRA, 2012).

\subsection{PRODETUR IE II: UM ANTES E UM DEPOIS NO NORDESTE}

Os Prodetur I e II contribuíram para mudanças significativas no litoral nordestino nas últimas décadas. O que chama atenção é a continuidade dos investimentos e o volume de capital para a implantação de infraestruturas nas cidades litorâneas com o objetivo de inserir suas praias no cenário internacional do turismo. Observando os mapas abaixo se poderá visualizar a quantidade de investimentos ao largo de todo o litoral dos estados da Bahia, Pernambuco, Rio Grande do Norte e Ceará.

O investimento do PRODETUR I na Bahia foi de R\$ 500 milhões, sendo investido prioritariamente em infraestrutura de suporte (BNB, 2005). Os investimentos e suas principais ações foram: os investimentos nos aeroportos de Salvador, Ilhéus e Porto Seguro (R\$ 214.014.520,21 milhões); investimento em Proteção Ambiental (R \$ 2.479.684,04 milhões); patrimônio histórico ( $\mathrm{R} \$ 18.410 .052,19$ milhões); e saneamento ( $\mathrm{R} \$$ 86.633.756,03 milhões), além dos investimentos em transportes, totalizados em R\$ 92.774.344,53 milhões.

O PRODETUR/BA teve dois papéis fundamentais, o primeiro de descentralizar o turismo para outras áreas, já que até a década de 1970 a cidade de Salvador aparecia como o único destino turístico, criando regiões prioritárias para investimentos do 
PRODETUR. E, o segundo papel foi o de internacionalizar os municípios polos dessas regiões como destinos turísticos: capital Salvador (Bahia de Todos os Santos e Costa do Dendê); Ilhéus; Porto Seguro e Lençóis, investindo prioritariamente em aeroportos (Salvador, Porto Seguro e Lençóis), com a intenção de recepcionar os turistas e distribuí-los aos municípios vizinhos e aos municípios polos (FIGURA 1).

No estado de Pernambuco, o investimento efetuado na primeira etapa do PRODETUR/NE foi de R $\$ 86$ milhões e teve como prioridade investimentos em infraestrutura de suporte, prioritariamente no Polo Costa Dourada, com ampliação e modernização do Aeroporto Guararapes ( $\mathrm{R} \$$ 6.310.894,98 milhões) em Recife; Investimento em Patrimônio Histórico (R 27.082.010,58 milhões) na Capital e em Olinda; e investimentos em Saneamento ( $\mathrm{R}$ 19.891.660,98 milhões) nos municípios de Recife, Rio Formoso e Sirinhaém (BNB, 2005).

Com o PRODETUR II - de investimento total de R \$ 293.712 milhões - o estado decide investir em todos os seus municípios litorâneos (BNB, 2010). O PRODETUR, em sua segunda fase, viabiliza a diversificação dos investimentos, em transportes ( $R$ \$ 166.478.212,62 milhões), Saneamento Básico ( $\mathrm{R} \$ 103.180 .069,64$ milhões) e Patrimônio Histórico (R\$ 3.281.873,37 milhões), também os investimentos em formação e capacitação de empresários e gestores públicos ( $\mathrm{R}$ \$ 193.151,15 milhões), com atuação na atividade turística, procurando, dessa forma, fortalecer uma das principais debilidades desse segmento e que estava atravessando sua inserção de modo mais competitivo no turismo globalizado, ou seja, a qualificação profissional; além de procurar reforçar em projetos de contenção dos riscos ambientais ( $\mathrm{R}$ \$ 596.670,25 milhões), como se observa em todas as metrópoles conforme (FIGURA 1). 
FIGURA 1 - INVESTIMENTOS PRODETUR I E II NOS ESTADOS DA BAHIA E PERNAMBUCO

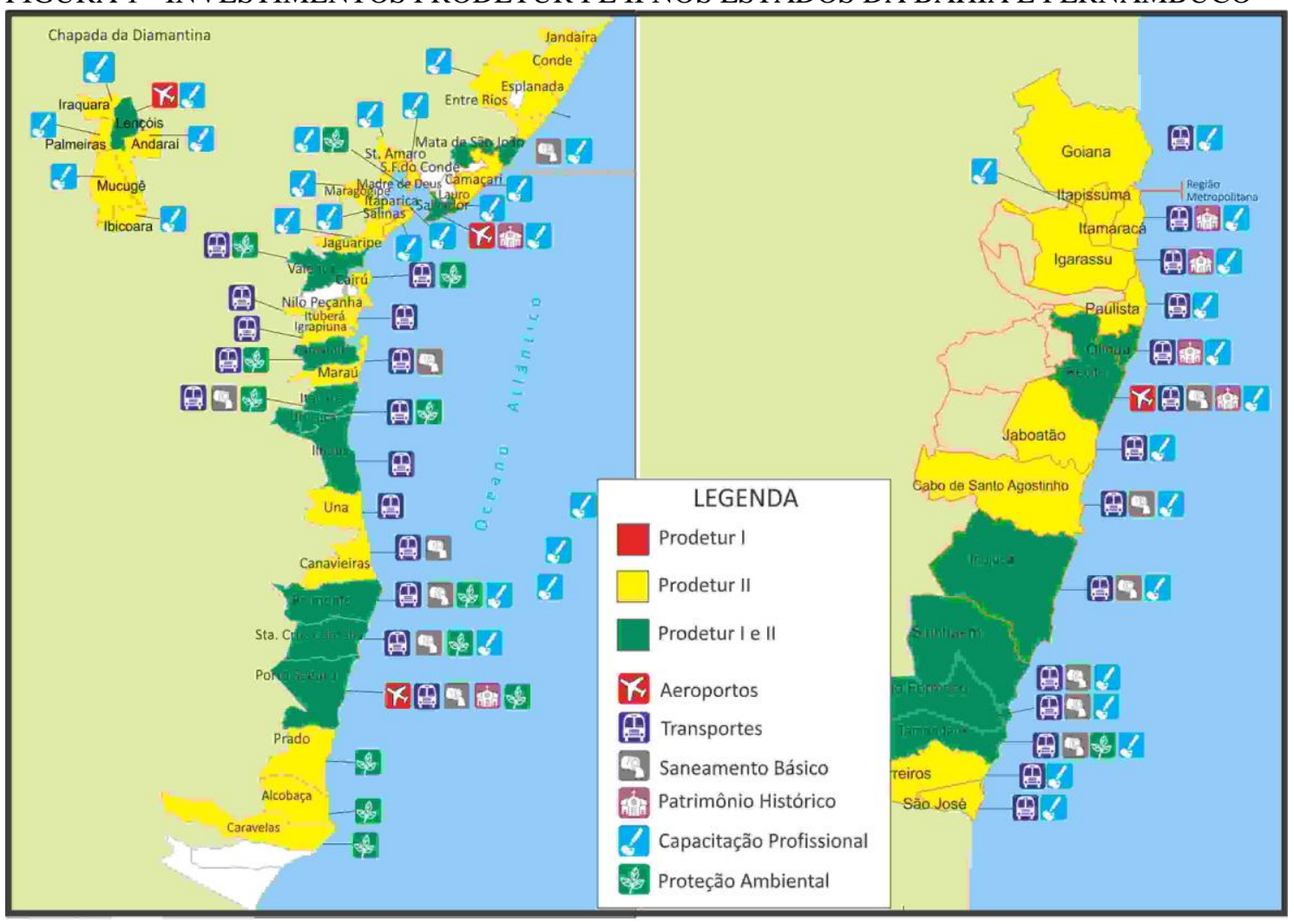

FONTE: Adaptado pela autora conforme BNB (2005; 2010).

No Rio Grande do Norte, como pode ser observado na Figura 2, houve investimentos na ampliação do aeroporto em Parnamirim ( $\mathrm{R}$ \$ 41.099.835,54 milhões), em Proteção Ambiental (R\$ 2.970.488,35milhões) e Saneamento (R\$ 11.558.972,09 milhões) no Parque das Dunas e praia de Ponta Negra/Natal (BNB, 2005). Com o

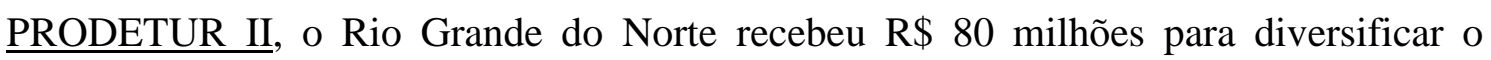
produto e qualificar os profissionais com a intenção de alcançar o mercado nacional e internacional. A região metropolitana de Natal recebeu a maior parte dos investimentos, sendo incorporados os municípios do Polo Costa das Dunas (FIGURA 2). 


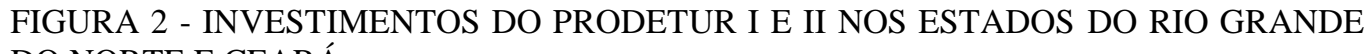
DO NORTE E CEARÁ

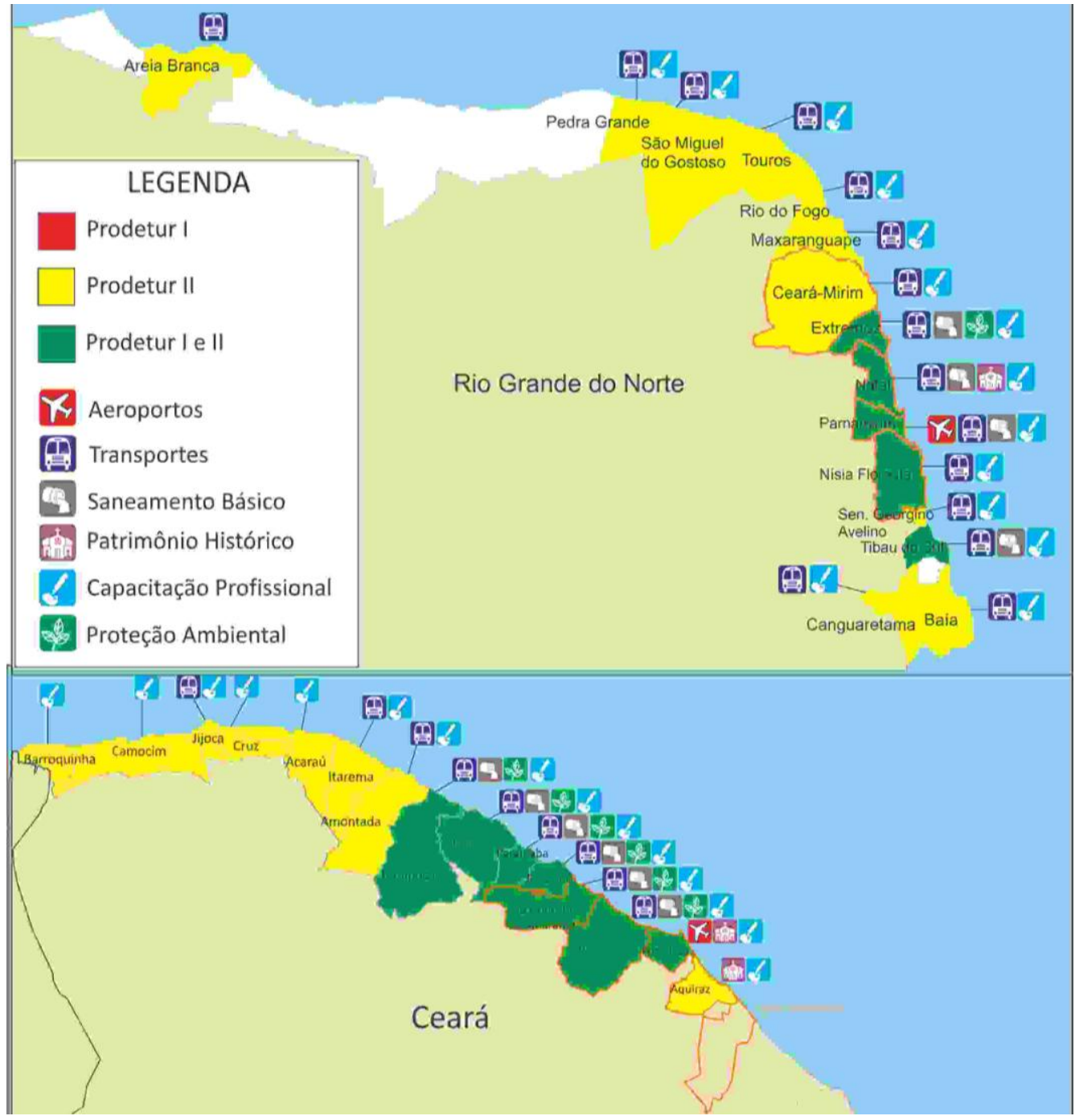

FONTE: Adaptado pela autora conforme BNB (2005); Observatório das Metrópoles (2012).

O estado do Ceará investiu R $\$ 268$ milhões na ampliação e modernização do Aeroporto Pinto Martins e os investimentos no sistema viário (estradas) viabilizaram a promoção da cidade de Fortaleza no cenário Internacional (BNB, 2005). O $\underline{\text { PRODETUR }}$ I investiu na ampliação e modernização do Aeroporto Internacional Pinto Martins (R\$ 149.053.132,13 milhões), Investimento em Proteção Ambiental (R \$ 10.064.874,74 milhões) e saneamento ( $\mathrm{R} \$$ 64.440.327,05 milhões) nos municípios de Itapipoca, Trairi, Paraipaba, Paracuru, São Gonçalo e Caucaia. Além dos investimentos em transportes, somados em R\$ 47.149.090,60 milhões em obras na CE 085, CE 162, CE 421 e CE 341, com o objetivo de promover as praias da Região Turística II e integrá-las no turismo cearense. 
Na segunda fase do Prodetur no Ceará, o montante total foi de R \$ 141 milhões priorizando investimentos na Região Metropolitana de Fortaleza (eixo oeste) e municípios vizinhos (BNB, 2010). Além de contemplar os municípios do litoral do extremo oeste, com o intuito de promover e dinamizar o fluxo turístico entre os estados do Ceará, Piauí e Maranhão (CEPIMA). Em relação aos investimentos em Transporte, foram investidos em municípios do extremo norte, que no caso, não receberam investimento do PRODETUR I. Foram investidos no total, R\$ 112.618.970,02 milhões nos municípios de Amontada, Itapipoca, Itarema e Jijoca; no caso do investimento em Patrimônio Histórico foram gastos R \$ 7.254.673,57 milhões na sede municipal de Fortaleza e Aquiraz; no segmento de Capacitação Profissional, o montante de R\$ 6.113.681,52 milhões investido no litoral oeste e município de Aquiraz.

\subsection{INTERIORIZAR, REGIONALIZAR E INTERNACIONALIZAR}

O PRODETUR Nacional é um programa regional de desenvolvimento do turismo, proposto a complementar o PRODETUR I e II, lançados ainda na década de 1990 e início dos anos 2000, respectivamente (DA SILVA; FREITAS SILVA; DE SOUSA, 2017). O Programa tem como objetivo de desenvolver a atividade turística de forma regionalizada, com foco no planejamento coordenado e participativo (BRASIL, 2007, p. 19). Além do Prodetur, se pode destacar também o Programa de Aceleração do Crescimento (PAC), que apesar de não ter como foco principal o turismo, acaba favorecendo-o, uma vez que seus investimentos são direcionados em infraestrutura como rodovias, aeroportos etc., que são indispensáveis para a internacionalização da atividade (ALVES; DE MEDEIROS; FARIAS, 2012; SILVA; FREITAS SILVA; SOUSA, 2017).

O programa iniciou com financiamento inicial de 1,6 bilhões de dólares e visou aumentar a competitividade dos destinos turísticos do país e consolidar a política de turismo regional por meio de um modelo de gestão pública descentralizada e cooperativa. Com o PRODETUR Nacional, o estado da Bahia assinou o contrato no dia 28 de julho de 2011, um financiamento junto ao Banco Interamericano de Desenvolvimento (BID) de R \$ 102 milhões, somados à contrapartida de R \$ 71 milhões, assumida pelo Ministério do Turismo (MTur), somando um montante de U\$ 173 
milhões (CONFIEX, 2012). O PRODETUR Nacional no estado da Bahia acabou priorizando especificamente o polo turístico da Bahia de Todos os Santos (FIGURA 3).

FIGURA 3 - MAPA PRODETUR NACIONAL E PAC POR COMPONENTE NOS ESTADOS DA BAHIA, PERNAMBUCO E CEARÁ.

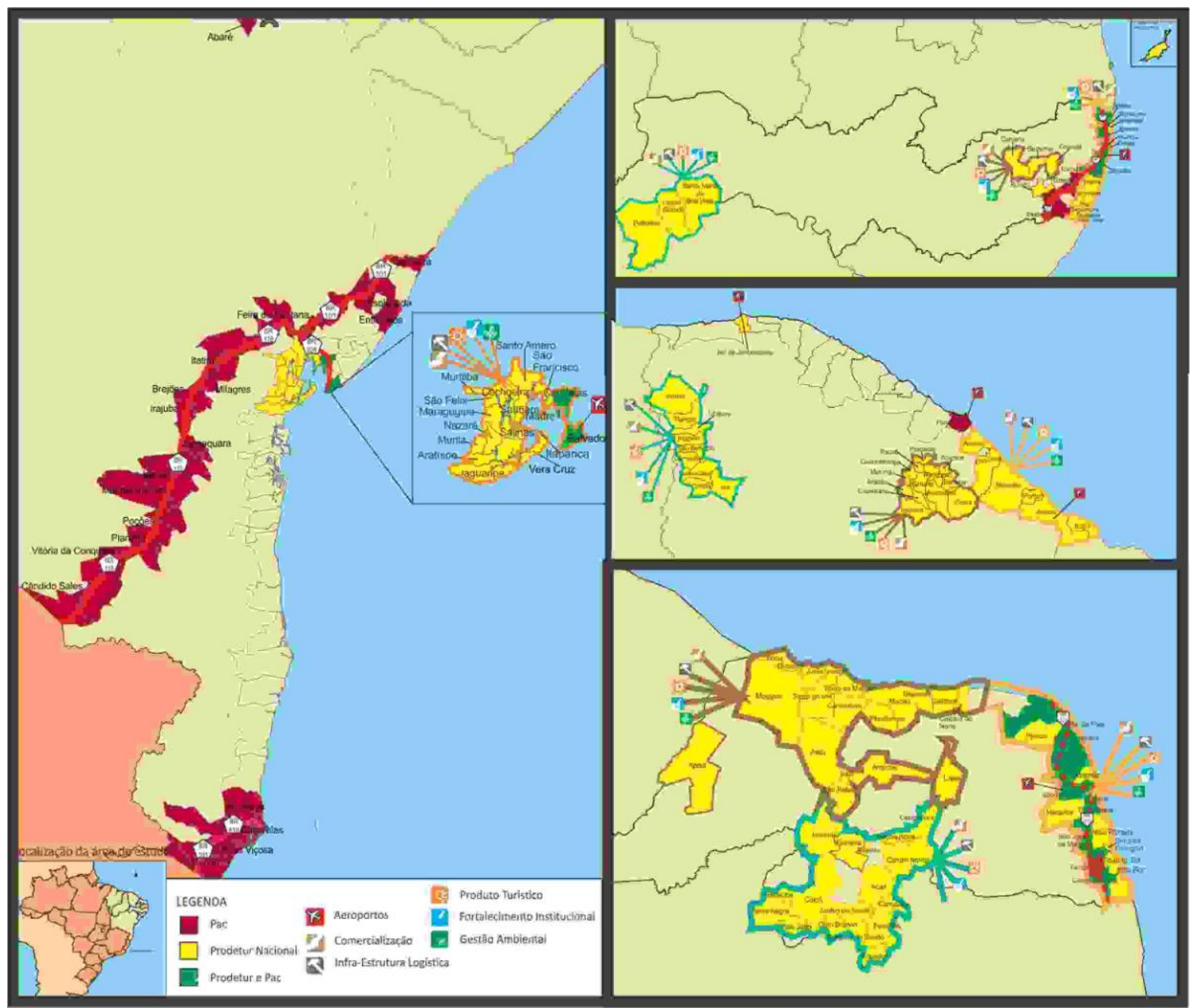

FONTE: Adaptado pela autora conforme Relatório PAC (2010); Confiex, (2012).

Em relação aos investimentos do Programa PAC no estado da Bahia foram investidos apenas em três anos (2007-2010) mais de 2 bilhões de reais e mais de 1 bilhão e 205 mil após 2010 (PAC, 2010). Os investimentos para o setor de turismo foram prioritariamente em aeroportos e vias de acesso. Foram investidos, portanto, no aeroporto de Salvador R \$ 3,8 milhões; em obras de pavimentação da BR 101 R 997,7 milhões; em obras de construção e concessão da BR's 324 R\$ 381 milhões; na BR 116 R\$ 1.900 milhões; e na BR 418 R \$ 86 milhões.

Em relação a Pernambuco o investimento do Prodetur nacional foi de $\mathrm{R} \$ 125$ milhões. O PRODETUR Nacional em Pernambuco destinou seus investimentos para 
todos os municípios litorâneos com a estratégia de integrar e consolidar a costa litorânea pernambucana como destino turístico internacional. Além disso, foram direcionados investimentos para segmentar, diversificar e interiorizar o turismo no estado. Neste contexto as regiões do Agreste e do vale do São Francisco receberam incentivos financeiros para construção de rodovias, gestão ambiental, qualificação profissional e fortalecimento institucional (FIGURA 3). O estado de Pernambuco também recebeu investimentos do PAC destinados para a ampliação do terminal de passageiros do Aeroporto de Recife (R \$ 10 milhões); e em obras de duplicação em toda a extensão da BR 101 no estado, movimentando um total de R\$1. 255,9 milhões só em rodovias.

No caso do Rio Grande do Norte, o estado recebeu uma carta de financiamento de $\mathrm{R} \$ 152$ milhões, sendo $\mathrm{R}$ \$ 61 milhões de contrapartida e $\mathrm{R} \$ 91$ milhões financiados pelo BID (CONFIEX, 2012). O PRODETUR Nacional no estado potiguar visou, assim como os demais estados, regionalizar, interiorizar e diversificar o segmento turístico. Em relação ao PAC, o Rio Grande do Norte recebeu investimentos para a construção de um aeroporto em São Gonçalo e para a pavimentação e duplicação da BR-101, rodovia que corta de norte a sul o Brasil, dando acesso às praias do litoral brasileiro.

Em relação ao estado do Ceará o financiamento junto ao BID foi de R \$ 305 milhões, somados à contrapartida de R $\$ 204$ milhões, assumida pelo MTur, somando um montante de $\mathrm{R} \$ 509$ milhões (CONFIEX, 2010). O estado do Ceará investiu nas suas principais regiões turísticas: serra da Ibiapaba, maciço de Baturité (Guaramiranga) e região do litoral leste. Foram construídos dois aeroportos regionais em Jericoacoara (Preá) e Aracati para promover e intensificar o turismo regional nestas áreas. No caso do PAC o investimento de 3,3 milhões foi destinado para a ampliação do aeroporto de Fortaleza, associado à dinâmica dos megaeventos (PAC, 2010).

\subsection{INVESTIMENTOS ESTRANGEIROS NAS METRÓPOLES}

Como já foi mencionado anteriormente, as políticas públicas tiveram e têm um papel importante no planejamento do turismo. A reconfiguração dos espaços litorâneos para o uso turístico e imobiliário não consiste em um fenômeno natural ou uma coincidência do acaso. Neste sentido o destaque do Nordeste como uma região alvo de investimentos turístico-imobiliários de capital nacional e internacional só foi possível, 
graças à construção de uma imagem positiva do semiárido somado aos investimentos das políticas públicas de turismo (PEREIRA; FREITAS SILVA, 2014). Nesse sentido, vale identificar para onde se direcionou o capital privado nos estados e se existiu alguma relação com os investimentos oriundos das políticas públicas de turismo.

Ao se observar os 66 empreendimentos (entre empreendimentos em operação e/ou em construção e/ou indefinido) oriundos de capital privado (entre resorts, condoresorts, complexos turísticos residenciais), é possível identificar que a maioria destes investimentos se concentraram em três áreas principais. Primeiramente na região metropolitana de Salvador, sobretudo nos municípios de Camaçari e Mata de São João. A concentração dos investimentos nessa região tem a ver com a facilidade no acesso (aeroporto internacional) e na distribuição do fluxo às praias metropolitanas (rodovias). Também é possível observar um processo disperso onde os investimentos se concentraram pontualmente nos municípios de Jandaíra e Conde (no litoral norte/linha verde/BA-099). Ademais da região Porto Seguro e vizinhança no litoral extremo sul (graças ao aeroporto regional).

O estado de Pernambuco, com $187 \mathrm{~km}$ de litoral e 21 municípios litorâneos, entre praias, falésias e espaços praticamente intocados, constitui-se como o menor litoral dentre os apresentados nesta pesquisa. Conforme figura 4 se pode observar que os investimentos de capital privado em Pernambuco se concentraram, quase que exclusivamente em dois municípios, Ipojuca e Cabo de Santo Agostinho. Em termos gerais os investimentos se concentraram na região metropolitana no estado. Portanto, apesar dos investimentos decorrentes do PRODETUR e PAC com o objetivo de atração, dispersão e diversificação do turismo para as diferentes áreas do território pernambucano, se encontra uma realidade estritamente metropolitana, com exceção de Tamandaré. 
FIGURA 4 - INVESTIMENTOS DO CAPITAL PRIVADO NOS ESTADOS DA BAHIA E PERNAMBUCO

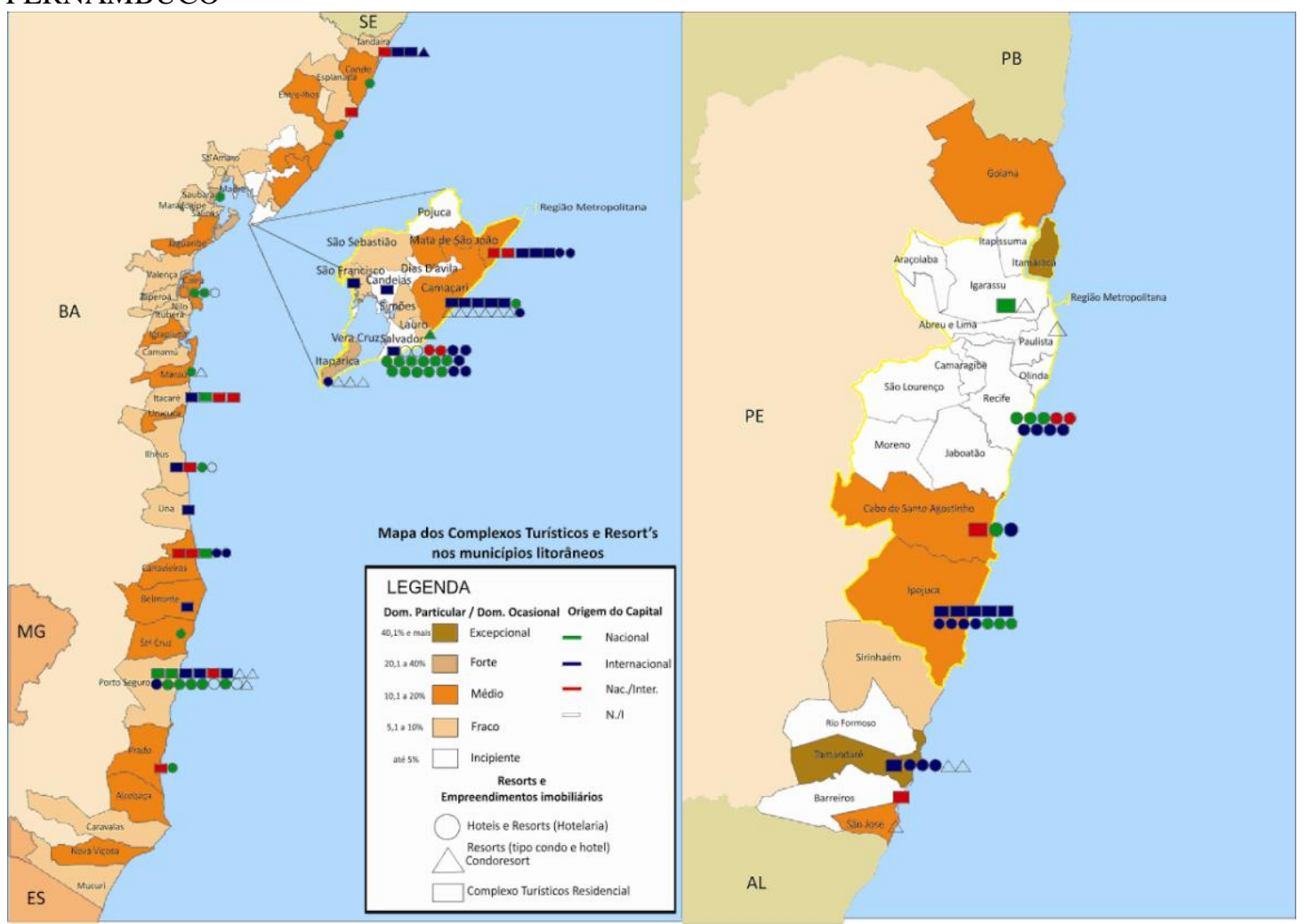

FONTE: Adaptado pela autora conforme, Freitas Silva (2013b); Araújo (2016); Censo (2010).

O estado do Rio Grande do Norte se destaca entre os estados do Nordeste pela atividade de segunda residência. Pode-se encontrar uma intensa atividade de produção de casas de uso ocasional/segunda residência em praticamente todo o litoral potiguar. A origem do capital e dos proprietários são quase que exclusivamente do próprio estado potiguar, da região sudeste e uma pequena parcela de turistas residenciais estrangeiros (DEMAJOROVIC, 2011).

Ao se observar a figura 5, se pode ver que a grande maioria dos empreendimentos do tipo turístico-imobiliário se concentra na região metropolitana potiguar, em uma lógica paralela à zona de praia, onde São Gonçalo recepta (novo aeroporto do Rio Grande do Norte) e distribui os fluxos aos municípios vizinhos. Entretanto é possível observar, também, que existe um processo de urbanização turística que ultrapassa os limites da região metropolitana. Investimentos que alcançam os municípios de Rio do Fogo, Touros e São Miguel do Gostoso (litoral norte) e Tibau do Sul (litoral sul). 
O estado do Ceará, com mais de $573 \mathrm{~km}$ de litoral, apresenta municípios que possuem índices que variam de incipiente a excepcional no tocante a residências secundárias. Como pode ser visto, a Região Metropolitana e os municípios do litoral leste concentram as maiores taxas de segundas residências e, também de investimentos turístico-imobiliários. O estado se situa a 6 horas de voo da Europa e com três aeroportos localizados estrategicamente na metrópole (Capital), litoral leste (Aracati) e litoral oeste (Jericoacoara), tem seu litoral atraente aos olhos de empresas e compradores de procedência europeia, nos últimos anos (ASSIS, 2009; FREITAS SILVA, 2013a). O estado passou a possuir 33 resorts, entre os empreendimentos exclusivamente hoteleiros e os associados ao componente imobiliário.

FIGURA 5 - INVESTIMENTOS DO CAPITAL PRIVADO NOS ESTADOS DO RIO GRANDE DO NORTE E CEARÁ

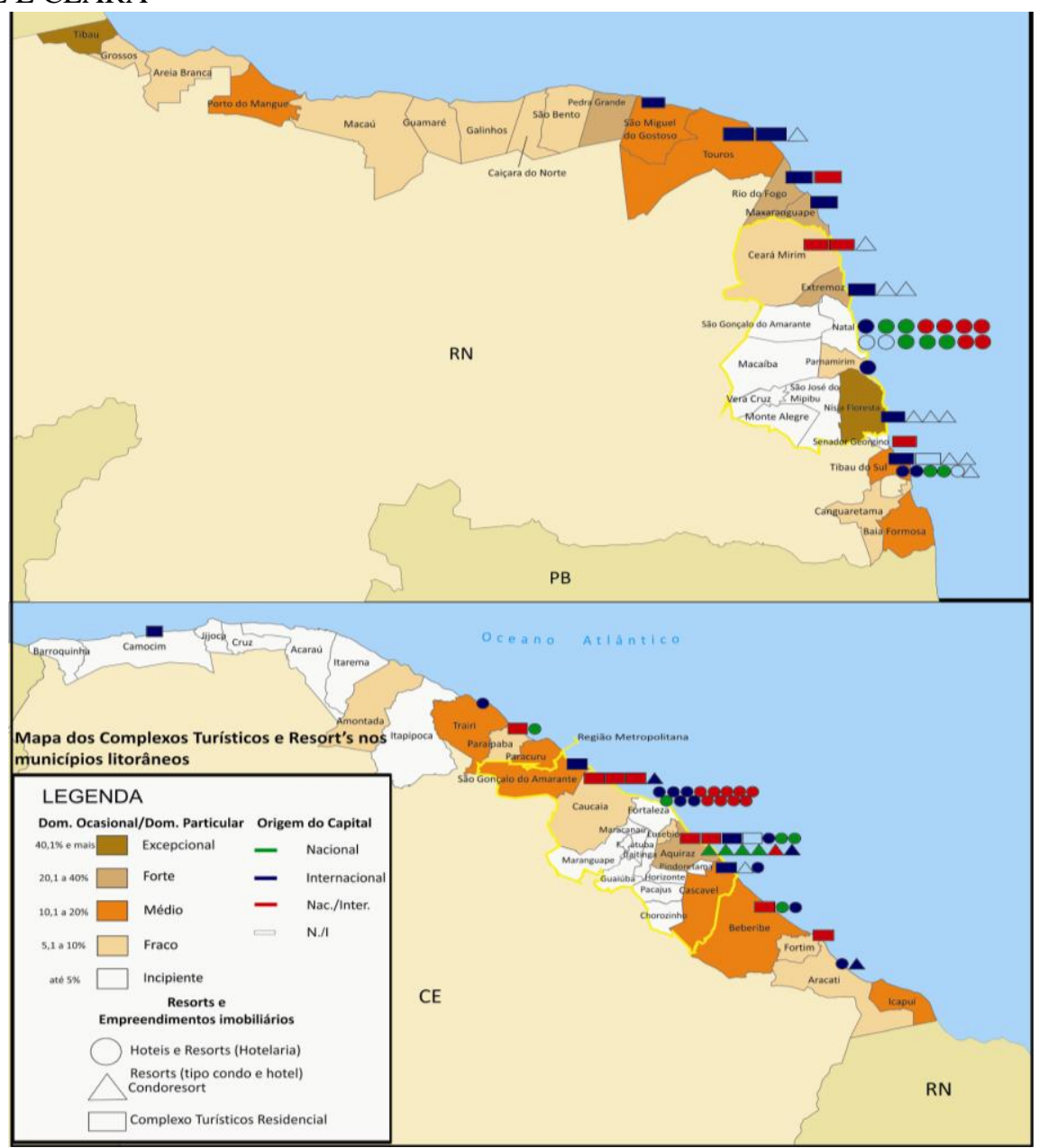

FONTE: Adaptado pela autora conforme; Freitas Silva (2013b); Araújo (2016); Censo, 2010. 


\section{CONSIDERAÇÕES FINAIS}

A Região Nordeste do Brasil vem sofrendo um processo contínuo de transformação e reconfiguração dos seus espaços litorâneos. A transformação progressiva das comunidades tradicionais em espaços turísticos passou a acontecer graças a continuidade de políticas públicas de turismo, ademais de um marketing produzido pela própria elite local desta região. Portanto, a promoção do turismo a "todo custo", vendida sobre uma abordagem utilitarista/economicista da atividade passou a contribuir para um processo de valorização, especulação e urbanização do litoral em curto tempo.

Verificou-se como resposta ao investimento de capital público nos espaços litorâneos, a inclusão dessa região no cenário turístico internacional, e consequentemente a atração de investimentos de capital estrangeiro. A região Nordeste deixa de ser uma região problema para tornar-se uma oportunidade para as atividades turísticas e imobiliárias. Nesse cenário de mudanças socioeconômicas é que o Nordeste passou a protagonizar um processo de reconfiguração territorial em função dos novos usos e usuários (turistas, empresas imobiliárias, corretoras, empresas de cambio etc.).

Passou a existir uma variedade de oferta imobiliária no Nordeste, desde lotes individuais a condomínios fechados, assim como uma oferta recente de condoresorts, casas de luxos em resorts "all inclusive", complexos turísticos residenciais com golfe e outros. Portanto se considera o papel do Estado, como financiador de infraestruturas, qualificação da mão de obra e no marketing dos destinos, em outras palavras um importante "corretor imobiliário" na região Nordeste.

Ademais, não se pode desconsiderar o fato que com o discurso economicista do desenvolvimento como um progresso linear, o PRODETUR Nacional passou a inserir outras regiões (não turísticas) como uma oportunidade de negócio (futuro) econômico nacional e internacional. Considera-se que esse projeto macrossocial de transformar o turismo em uma política nacional de governo (de cima para baixo), sem filtro - sem planejamento participativo - em um processo consensual entre capital público e privado pode ser um caminho sem volta, e altamente impactante às comunidades.

Portanto, para finalizar o artigo, mas não a discussão deixa-se três questões/desafios principais como reflexão e desafio para futuras pesquisas: 
1) As comunidades locais estão sendo beneficiadas? Como identificar?

2) O Estado é capaz de conter as pressões do capital privado? Como provar?

3) O turismo e as políticas públicas estão realmente contribuindo para o desenvolvimento local? Como analisar?

\section{REFERÊNCIAS}

ARAÚJO, C. P. "Paraísos à beira-mar": os empreendimentos turísticos imobiliários. In: VARGAS, H. C.; PAIVA, R. A. (Org.). Turismo, arquitetura e cidade. 1. ed. Barueri: Manole, 2016, p. 111-132.

ARCHER, B.; COOPER, C. Os impactos positivos e negativos do turismo. Turismo global, v. 2, 2001.

ASSIS, L. F. de. Turismo sustentável e globalização: Impasses e perspectivas. Revista da Casa da Geografia de Sobral (RCGS), 2002, v. 4, n. 1.

"Segundas residencias y multiterritorialidad en el nordeste brasileño: el aumento del turismo residencial". In: MAZÓN, T.; HUETE, R.; MANTECÓN, A. (Eds.) Turismo, urbanización y estilos de vida. Las nuevas formas de movilidad residencial. Barcelona: Icaria, 2009, p. 175-191.

BANCO DO NORDESTE DO BRASIL (BNB). Relatório final do Prodetur I, 2005.

Disponível em: <http://www.bnb.gov.br/content/aplicacao/PRODETUR/prodetur _ne1/gerados/a presentacao.asp> Acesso em: 08/09/2017.

"Relatório Final do Prodetur II", 2010. Disponível em:

$<$ http://www.bnb.gov.br/content/aplicacao/PRODETUR/prodetur_ne2/gerados/apres entacao.asp>. Acesso em: 08/09/2018.

BENEVIDES, I. P. Para uma agenda de discussão do turismo como fator de desenvolvimento local. In: RODRIGUES, A. B. (org.). Turismo e desenvolvimento local. São Paulo: HUCITEC, 1997, p. 23-41.

BENI, M. C. Análise estrutural do turismo. 4. ed. rev. São Paulo: SENAC, 2001.

Política e estratégia de desenvolvimento regional: planejamento integrado do turismo. In: RODRIGUES, A. B. (Org.) Turismo e desenvolvimento local. 3. ed. São Paulo: Hucitec, 2002. cap. 6. 
BRASIL. Ministério do Turismo. Coordenação Geral de regionalização. Programa de Regionalização do turismo - Roteiros do Brasil: Ação Municipal para regionalização do Turismo. Ministério do Turismo. Secretaria Nacional de políticas de Turismo. Departamento de Estruturação, articulação e ordenação turística, Brasília, 2007.

BRITTON, S. The Political Economy of Tourism in the Third World. Annals of Tourism Research, 1982, v. 9, n. 3, p. 331- 358.

BUTLER, R. Sustainable tourism: Looking backwars in order to progress? In: HALL, M.; LEW, A. (eds.). Sustainable tourism: a geographycal analysis. Essex, UK: Addison Wesley Longman Limited, 1998. p. 25-34.

CANDIOTTO, L. Turismo rural na agricultura familiar: uma abordagem geográfica do Circuito Italiano de Turismo Rural (CITUR). 397 f. Tese (Doutorado) Universidade Federal de Santa Catarina, Florianópolis, município de Colombo-PR. 2007.

CANDIOTTO, L.; ZANETTI, P. Considerações sobre o conceito de turismo sustentável. Formação. Presidente Prudente, v. 1, n. 16, 2009, p. 48-59.

COMISSÃO DE FINANCIAMENTOS EXTERNOS (CONFIEX). Relatório dos Projetos dos estados e municípios. Ministério do Planejamento, Secretaria de Assuntos Internacionais, 2012. Disponível em: <http://www.planejamento. gov.br/secretarias /upload/Arquivos/seain/downloads/2013/130204_Estados_ e_Muni cipios.pdf>. Acesso em: 02/02/2016.

COSTA, H. S. M. Meio ambiente e desenvolvimento: um convite à leitura. In: HISSA, C. E. V. (org.). Saberes ambientais. Desafios para o conhecimento disciplinar. Belo Horizonte: Editora UFMG, 2008, p. 79-117.

CRUZ, R. A. Planejamento governamental do turismo: convergências e contradições na produção do espaço. In: LEMOS, A. I. G; ARROYO, M.; SILVEIRA, M. L. América Latina: cidade, campo e turismo. CLACSO: San Pablo, 2006.

DA SILVA, M. M. N.; FREITAS SILVA, M. N. DE; DE SOUSA, N. G. S. Interiorização, Regionalização e Internacionalização do turismo no Nordeste. In: A cidade e o urbano, contribuição da Geografia: que teorias para este século? Anais... XV ENCONTRO NACIONAL DO SIMPURB. Salvador: SIMPURB, 2017.

DANTAS, E. W. C. Construção da imagem turística de Fortaleza/Ceará. Mercator: Revista de Geografia da UFC, ano 1, n. 1, 2002.

Imaginário social nordestino e políticas de desenvolvimento do turismo no Nordeste brasileiro. GEOUSP: Espaço e Tempo (Online), 2007, n. 22, p. 09-30.

Programa de Desenvolvimento do turismo no Nordeste Brasileiro (1995 a 2005); Prodetur-NE, o divisor de águas. In: Turismo e imobiliário nas metrópoles. DANTAS, E. W. C. (orgs.). 1. ed. v. 1. Rio de Janeiro: Letra Capital, 2010. 224 p. 
DE ALMEIDA, M. G. Desenvolvimento turístico ou desenvolvimento local? Algumas reflexões. Anais do ENTBL - planejamento para o desenvolvimento local. Curitiba Paraná, 2004.

DEMAJOROVIC, J.; ALEDO, A. LANDI, B.; KONDO, A. L. Complejos Turísticos Residenciales. Análisis del crecimiento turístico residencial en el Mediterráneo español y en el Litoral Nordestino (Brasil) y sus impactos socio-ambientales, Estudios y perspectivas en Turismo, 2011, v. 1, n. 20, p. 772-796.

DIAS, R. Planejamento do turismo: política e desenvolvimento do turismo no Brasil. São Paulo: Atlas, 2003.

ENDRES, A. V. Políticas de turismo, desenvolvimento e o papel do estado: cenários e inquietações. Em Tese, v. 5, n. 1, p. 74-97, 2008.

ESTEVA, G. Desenvolvimento. In: SACHS, W. (ed.). Dicionário do desenvolvimento - guia para o conhecimento como poder. Petrópolis: Vozes, 2000, 399 p.

FREITAS SILVA, M. N. de. Os resorts residenciais na região metropolitana de Fortaleza (Ceará, Brasil). Turismo e Sociedade, Curitiba, v. 6, n. 1, 2013 a.

FREITAS SILVA, M. N. de. O imobiliário-turístico no nordeste brasileiro: o turismo residencial e a macrourbanização turística a partir expansão e expressão dos resorts residenciais no litoral. 143 f. Dissertação (mestrado) - Universidade Federal do Ceará, Centro de Ciências, Departamento de Geografia, Programa de Pós-Graduação em Geografia, Fortaleza, 2013b. 144 p.

GOELDNER, C. R.; RITCHIE, J. R. B.; MCINTOSH, R. W. Turismo: princípios, práticas e filosofias. 8. ed. Porto Alegre: Bookman, 2002.

GOMES, G. M. Ideias para a modernização do Nordeste. In: VELOSO, J. P. dos R. (org.) Brasil em mudança: Fórum Nacional. São Paulo, Nobel, 1991. p. 235- 250.

JAFARI, J. El turismo como disciplina científica. Política y sociedad, v. 42, n. 1, p. 39$56,2005$.

KO, T. G. Assesing progress of tourism sustainability. Annals of Tourism Research, 2001, 28 (3): p. 817-820.

KRIPPENDORF, J. Towards New Tourism Policies: The importance of environmental and socio-cultural factors. Tourism Management, 1982, v. 3, p. 135-148.

LOHMANN, G.; PANOSSO NETO, A. Teoria do turismo - conceitos, modelos e sistemas. São Paulo: Editora Aleph, 2008 (serie turismo). 468 p.

MALTA, G. A. P.; BARBOSA, M. F. P. Turismo e desenvolvimento: reflexões acerca de uma complexa relação. Revista Brasileira de Ecoturismo, São Paulo, v. 6, n. 5, nov. 2013/jan. 2014, p. 862-895. 
MOLINA, S.; RODRIGUEZ, S. Planejamento integral: um enfoque para a América Latina. Bauru - SP, EDUSC, 2001.

PEREIRA, A. Q. Das cidades às metrópoles litorâneas: o papel da vilegiatura marítima moderna no Nordeste do Brasil. GEOUSP: Espaço e Tempo (Online), 2012, n. 31, p. $05-15$.

PEREIRA, A. Q.; FREITAS SILVA, M. N. de. O litoral nordestino e o imobiliárioturístico: Bahia, Pernambuco, Ceará e Rio Grande do Norte. GeoTextos, 2014, v. 10, n. 1.

PROGRAMA DE ACELERAÇÃO DO CRESCIMENTO (PAC). Relatório do PAC Bahia, Pernambuco, Rio Grande do Norte e Ceará, 2010. Disponível em: <http://www.pac.gov.br/estados>. Acesso em: 08/08/2017.

REIS, M. C. Apreensão da realidade, projetos políticos em disputa e desenvolvimento: Notas a partir das contribuições de Fernad Braudel, Norbert Elias e Boaventura de Sousa Santos, Belo Horizonte. Anais... do XII CONGRESSO BRASILEIRO DE SOCIOLOGIA, 2005.

RODRIGUES, A. A. B. Turismo: desenvolvimento local. São Paulo: HUCITEC, 1997.

SINCLAIR, M. T.; STABLER, M. Aspectos econômicos do turismo. Brasília: Editora Universidade de Brasília, 2009.

SOLHA, K. T.; TULIK, O. Órgãos públicos estaduais e o desenvolvimento do turismo no Brasil. 2004. 178f. Tese (Doutorado em Relações Públicas, Propaganda e Turismo). Escola de comunicações e Artes da Universidade de São Paulo, São Paulo, 2004.

STREETEN, P. Culture and economic development. In: GINSBURGH, V. A.; THROSBY, D. (Eds.) Handbook of the economic of art and culture. Amsterdam: Elsevier, 2006. v. 1, p. 400-412.

TOSUN, C.; JENKINS, C. L. The evolution of tourism planning in third-world countries: A critique. Progress in Tourism and Hospitality Research, 1998, v. 4, n. $2,101 \mathrm{p}$.

Recebido em : 02-02-2108.

Aprovado em : 02-03-2018.

Versão final para publicação : 01-12-2018. 